\title{
O Jornalismo de Cinema em Portugal: da cobertura online à estreia dos filmes de $2019^{1}$
}

Film journalism in Portugal: online coverage of the 2019 film premiere

\begin{abstract}
Jaime Lourenço - Universidade Autónoma de Lisboa
NIP-C@M

Iscte / CIES - Instituto Universitário de Lisboa jlourenco@autonoma.pt

https://doi.org/10.26619/978-989-9002-14-2.5
\end{abstract}

\begin{tabular}{|c|c|c|}
\hline Recebido / Received & Aceite / Accepted & Publicado / Published \\
29.05 .2020 & 02.06 .2020 & 15.01 .2021 \\
\hline
\end{tabular}

Como citar este capítulo / How to quote this chapter:

Lourenço, J. (2021). "O Jornalismo de cinema em Portugal: da cobertura online à estreia dos filmes de 2019". In Lourenço, J. \& Lopes, P., Comunicação, Cultura e Jornalismo Cultural. Lisboa: NIP-C@M \& UAL. (pp. 93-110), disponível em https://repositorio.ual.pt/handle/11144/4753 DOI https://doi. org/10.26619/978-989-9002-14-2.5

1 Este capítulo está enquadrado na investigação de doutoramento "Jornalismo de Cinema em Portugal", financiada e apoiada pela Fundação para a Ciência e a Tecnologia (FCT), com a referência SFRH/BD/143752/2019.

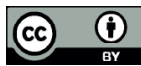




\section{Resumo}

No âmbito da nossa investigação de doutoramento, financiada pela FCT, procuramos conhecer as características da cobertura jornalística à estreia dos filmes de 2019 pela imprensa online portuguesa.

O Jornalismo de Cinema constitui um objecto de estudo ainda muito pouco explorado pelas ciências sociais e da comunicação. Encarado como um subgénero do Jornalismo Cultural, o Jornalismo de Cinema assume-se como um campo de sentido informativo, crítico e pedagógico.

O presente artigo procura, a partir da análise de conteúdo às páginas online dos principais órgãos de comunicação social portugueses (Público, Correio da Manhã, Jornal de Notícias, Diário de Notícias, Expresso e Observador), do programa de rádio Cinemax, da Antena 3 e do programa de televisão Cinebox, da TVI24, identificar as características da cobertura mediática aos filmes que estrearam no ano de 2019.

Desta forma, propomos analisar a cobertura jornalística destes filmes no momento da sua estreia, destacando o enfoque, os géneros jornalísticos dominantes, os protagonistas destacados, o âmbito em que o filme é mencionado e as opções multimédia utilizadas nas páginas online destes órgãos de comunicação social. 


\section{Abstract}

As part of our phD research, funded by FCT, we seek to know the characteristics of the 2019 film premiere's journalistic coverage by the Portuguese online press.

Film Journalism is an object of study explored very little by the social sciences and communication. Seen as a subgenre of Cultural Journalism, Film Journalism is assumed as a field of informative, critical and pedagogical sense.

This chapter seeks, from the analysis of content to the online pages of the main Portuguese media agencies (Público, Correio da Manhã, Jornal de Notícias, Diário de Notícias, Expresso e Observador), the radio program Cinemax, Antena 3 and the television program Cinebox, TVI24, to identify the characteristics of the media coverage of films that debuted in 2019.

In this way, we propose to analyze the journalistic coverage of these films at the time of their debut, highlighting the focus, the dominant journalistic genres, the highlighted protagonists, the scope in which the film is mentioned and the multimedia options used in the online pages of these media. 


\section{Jornalismo de Cinema: breve contexto}

A propósito do ciclo "Jornalismo \& Cinema", inserido nas comemorações do 20ำ aniversário do semanário Expresso, em 1993, o seu fundador, Francisco Pinto Balsemão referia que "os homens dos jornais sempre manifestaram, por seu lado, um interesse quase anormal pelo cinema" (Balsemão, 1993: 9).

O jornalismo de cinema, enquanto especialização, possuí as mesmas características distintivas do jornalismo cultural, mas aplicadas ao contexto cinematográfico. Algumas dessas características são a democratização do conhecimento, ao dar a conhecer e tornar acessível determinadas obras, bens e pensamentos. $\mathrm{O}$ carácter reflexivo que está impresso no género de excelência do jornalismo de cinema (e do cultural), a crítica e a dimensão performativa em que o jornalismo contribui para que o leitor/ouvinte/espectador desencadeie uma ação (por exemplo, ir ver um filme ou comprar um DVD).

Balsemão defendia, já em 1993, que o cinema era parte integrante do jornalismo, pois existiam "cada vez mais publicações escritas, a televisão, a própria rádio ocupam-se do cinema, precisam do cinema, noticiam o cinema, usam o cinema" (Balsemão, 1993: 9).

Sendo o papel do jornalismo "fornecer aos cidadãos a informação de que precisam para serem livres e se autogovernarem" (Kovach \& Rosenstiel, 2005: 16), no que diz respeito à especia- 
lização em jornalismo de cinema essa função não é deixada de lado. Para Mário Mesquita, referência incontornável dos estudos de jornalismo em Portugal, "a informação especializada deve ser 'divulgação contextualizada', sem se confundir com uma 'vulgarização' que signifique ausência de rigor e caricatura do saber, a reboque das estratégias e dos interesses do 'marketing cultural'"' (Mesquita, 2001).

É neste sentido que Balsemão referia que,

"há que acompanhar a vida dos realizadores e dos actores. Há que noticiar os filmes em preparação. Há que dar relevo aos lançamentos comerciais das grandes produções, normalmente americanas, mesmo que não sejam grandes filmes" (Balsemão, 1993: 10).

Portanto, os filmes, nomeadamente as grandes produções (como os blockbusters ${ }^{1}$ ), enquanto fenómeno cultural representam notícias culturais, seja devido a fatores económicos, à presença de grandes celebridades, à inovação tecnológica que é aplicada nos filmes, ou até as campanhas de marketing que são implementadas em torno deste (Kristensen \& From, 2013: 53).

Deste modo, o Jornalismo de Cinema, enquanto um subgénero do Jornalismo Cultural, versa sobre o Cinema enquanto manifestação artística e indústria cultural com objetivos informativos, que promove a reflexão sobre a produção e cultura cinematográfica (independentemente da sua origem e destino), o discurso da cinefilia e o consumo de filmes.

1 São filmes populares entre o público, com um elevado custo de produção e, por conseguinte, um elevado sucesso financeiro a nível de bilheteira. 
Numa análise feita ao programa Cinebox, da TVI24 observou-se que as rotinas associadas ao jornalismo de cinema (praticado neste programa de televisão) são estruturadas em função do calendário definido pelos estúdios e distribuidoras, sendo a estreia de um filme um momento determinante dessa atividade jornalística (Lourenço, 2016: 123). É, neste sentido, que "os media raramente são a força condutora por trás das notícias, muitos dos conteúdos pertencem à agenda e disseminação de actividades planeadas" (Santos Silva, 2015: 65), neste caso da indústria cinematográfica.

Atualmente, não existe, em Portugal, nenhuma publicação dedicada exclusivamente ao cinema, colocando a informação sobre o cinema apenas nas páginas (impressas e online) da imprensa generalista, onde o cinema se constitui como uma das manifestações artísticas e culturais com maior presença (Baptista, 2014). Já na televisão e rádio, existem programas informativos que se debruçam exclusivamente sobre o universo cinematográfico: Cartaz Cinema (SIC Notícias), Janela Indiscreta (RTP), Cinebox (TVI24), Cinetendinha (SICRadical e TVCine), A Grande llusão (Antena2) e Cinemax (Antena1 e Antena3).

\section{Âmbito, corpus e metodologia da análise}

O presente artigo propõe analisar a cobertura jornalística que foi feita à estreia dos filmes que marcaram presença em Portugal ao longo do ano de 2019. O corpus desta investigação é composto pelas versões online dos principais jornais portugueses (Pú- 
blico, Correio da Manhã, Jornal de Notícias, Diário de Notícias, Expresso e Observador) e dos programas de rádio (Cinemax, da Antena3) e de televisão (Cinebox, da TVI24) especializados em cinema.

Analisaram-se os contextos em que a estreia destes filmes surgiu nas páginas online destes jornais e programas, o destaque que mereceram por parte destes, os géneros jornalísticos utilizados, os protagonistas destacados e as fontes que foram ouvidas.

Este estudo é parte integrante de uma investigação mais alargada que percorre toda a cobertura jornalística no que diz respeito ao cinema ao longo do ano de 2019.

\section{Jornalismo e indústria cinematográfica: uma relação calendarizada}

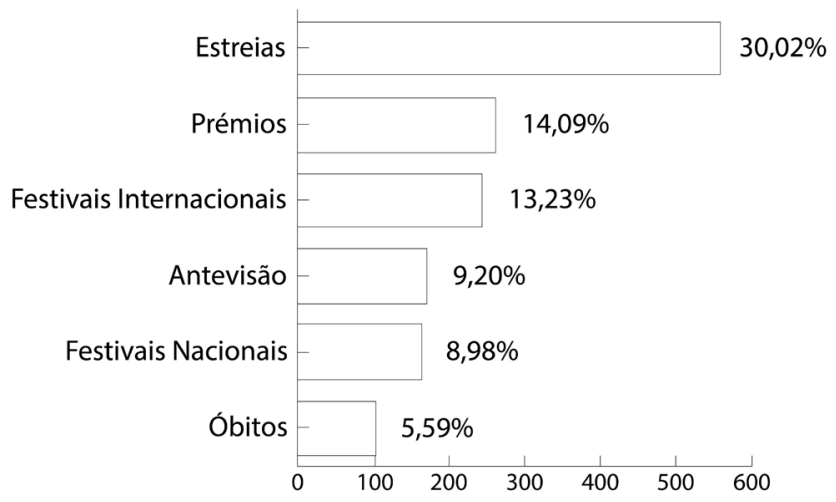

Gráfico 1: seis principais temas na cobertura jornalística online sobre cinema. 
A análise realizada permitiu perceber que, ao longo do ano de 2019, a cobertura jornalística online à área do cinema ocorreu, sobretudo, no momento da estreia dos filmes (Gráfico 1), seguida dos momentos de entrega de prémios, dos festivais internacionais, das antevisões, dos festivais nacionais, dos óbitos de figuras com ligação à atividade cinematográfica, entre outros.

Do ponto de vista da produção cinematográfica, a estreia é um momento em que um filme deixa de pertencer à equipa de produção e passa a estar acessível ao público nas várias salas de cinema do país (ou nas plataformas de streaming como a Netflix ou a HBO). É um momento que, no caso de grandes produções como blockbusters, visa um grande investimento a nível de divulgação e marketing.

Em Portugal, estrearam, em 2019, mais de 400 produções cinematográficas ${ }^{2}$, além dos filmes exibidos nas plataformas de streaming.

O calendário de estreias é definido pela indústria cinematográfica, mais concretamente entre as distribuidoras e as exibidoras de cinema. Esta agenda do universo cinematográfico a que, além das estreias, se juntam os festivais, as cerimónias de prémios, etc., é constante ao longo dos anos com uma estrutura que se repete de ano a ano. Estas circunstâncias levam a que os jornalistas que se dedicam ao cinema estejam confinados a uma agenda que é fortemente condicionada, na sua quase totalidade, pela indústria cinematográfica.

2 De acordo com os dados de exibição e estreias do Instituto do Cinema e do Audiovisual. 
Ora, do ponto de vista jornalístico, a estreia constitui-se como o principal momento de noticiabilidade, uma vez que é a partir dessa altura que o público tem acesso à obra e porque lhe confere um carácter de atualidade enquanto valor-notícia.

Contudo, uma das críticas mais frequentes ao jornalismo cultural (e consequentemente ao jornalismo de cinema) é a cobertura, praticamente exclusiva, das agendas de eventos das distribuidoras e a ausência de conteúdos fora do cartaz (Santos Silva, 2012: 96). Por sua vez, José Faro (2014) observa que esta realidade tem consequências como o empobrecimento da agenda cultural, uma abordagem superficial dos factos, a perda de substância nas reportagens e o sucesso dos departamentos de marketing (Faro, 2014). Já Daniel Piza (2003) critica o facto de a produção jornalística dedicada à cultura estar fortemente focada nos momentos de antecedência e lançamento dos produtos culturais enquanto que mais tarde, depois de os produtos já se terem estabelecido e terem tido uma "carreira", pequena que seja, deixa de haver espaço e tempo para refletir sobre o significado destes para o público (Piza, 2003: 51).

\section{Os filmes em estreia, uma presença constante}

As investigadoras dinamarquesas Nete Kristensen e Unni From (2013) referem que a imprensa dedicada ao cinema cada vez mais recorre às estreias de blockbusters como uma oportunidade para abordar estes filmes de forma analítica e reflexiva nas várias peças jornalísticas, contribuindo para a discussão sobre o filme enquanto um fenómeno cultural, tendo em conta propó- 
sitos comerciais e publicitários (Kristensen \& From, 2013: 61). Os blockbusters, ou os filmes de grande escala, têm sido e continuam a ser um objeto relevante do jornalismo de cinema.

Verificou-se que, durante o período de estreia, os filmes com o maior número de peças jornalísticas nas páginas online dos jornais e programas analisados são algumas das grandes produções cinematográficas que marcaram o ano de $2019^{3}$ (Tabela1). É o caso de Joker e O Rei Leão (os dois filmes mais vistos em 2019 no país ${ }^{4}$ ), bem como Star Wars, Era Uma Vez em Hollywood ou a produção da Netflix, O Irlandês.

Por sua vez, também houve uma preocupação por parte dos jornalistas que tratam as matérias de cinema em produzir várias peças jornalísticas sobre filmes portugueses aquando da estreia destes. Os mais mencionados foram: Variações, A Herdade, Diamantino, Linhas Tortas e Technoboss.

\begin{tabular}{ll}
\multicolumn{1}{c}{ Filme } & $\begin{array}{l}\text { Percentagem de peças } \\
\text { aquando a estreia }\end{array}$ \\
\hline Joker & $0,9 \%$ \\
Variações & $0,8 \%$ \\
O Irlandês & $0,7 \%$ \\
Star Wars: Episódio IX - A Ascensão de & $0,6 \%$ \\
Skywalker & $0,6 \%$ \\
O Rei Leão & $0,5 \%$ \\
A Herdade & $0,5 \%$ \\
Diamantino &
\end{tabular}

3 De acordo com Francisco Ferreira no artigo "Onde vamos ver os filmes?", publicado na revista E do semanário Expresso (Ferreira, 2019).

4 Segundo dados de bilheteira de 2019 disponibilizados pelo Instituto do Cinema e do Audiovisual. 


$\begin{array}{ll}\text { O Cavalheiro com Arma } & 0,5 \% \\ \text { Linhas Tortas } & 0,4 \% \\ \text { Technoboss } & 0,4 \% \\ \text { Toy Story } 4 & 0,4 \% \\ \text { Downtown Abbey } & 0,4 \% \\ \text { Era Uma Vez em Hollywood } & 0,4 \% \\ \text { Rocketman } & 0,4 \%\end{array}$

Tabela 1 Filmes com maior cobertura jornalística online à sua estreia em 2019.

A este respeito, na investigação dedicada ao Cinebox da TVI24, constatou-se que tanto a proximidade enquanto critério de noticiabilidade como a facilidade em contactar diretamente com os agentes portugueses (as produtoras nacionais, atores e realizadores) são contributos determinantes para a realização de vários conteúdos informativos sobre o cinema nacional (Lourenço, 2016: 121; Lourenço \& Subtil, 2017: 245).

Curiosamente, o filme que estreou este ano e se tornou no mais visto de sempre em todo o mundo - Os Vingadores: Endgame ${ }^{5}$ teve uma estreia pouco presente nas páginas online dos jornais portugueses.

Ainda neste quadro, algumas peças jornalísticas sobre as estreias dos filmes Joker ou $O$ Irlandês (maioritariamente publicadas nos jornais Público e Observador) foram das mais partiIhadas nas redes sociais pelos leitores. A título de exemplo, um artigo sobre o filme Joker, publicado no P3, do Público, teve mais de 15.000 partilhas. Quanto às estreias de filmes portugueses, 5 Em Portugal, foi o terceiro filme mais visto de 2019, segundo dados de bilheteira de 2019 disponibilizados pelo Instituto do Cinema e do Audiovisual. 
foram peças sobre a estreia dos filmes Vitalina Varela, Snu e o documentário Tony, as mais partilhadas.

No que diz respeito aos protagonistas das peças jornalísticas são os realizadores que ganham maior destaque, seguidos dos atores. Isto deve-se ao facto de se encarar a figura do realizador como o autor e responsável pela obra cinematográfica, estando, por isso, em grande maioria associado a qualquer filme que é tratado pelos media.

\section{Estreias sem recurso a fontes}

Do corpus de análise, os três jornais com o maior número de peças dedicadas ao cinema publicadas na sua versão online, ao longo do ano de 2019, foram o Público (30,8\%), o Observador (22,5\%) e o Jornal de Notícias (12,5\%).

Em grande parte das peças aquando das estreias de filmes não houve recurso a fontes para a redação das peças jornalísticas. Por sua vez, quando existiram fontes, foram os artistas (realizadores, atores, etc.) o principal recurso a que os jornalistas recorreram. Ora, as fontes de informação jornalística constituem-se como ponto fulcral para a compreensão dos conteúdos jornalísticos (Lopes, 2016) e o facto de estas não estarem presentes na produção jornalística nos momentos com maior frequência na área do cinema (estreias) entende-se como um empobrecimento do discurso jornalístico, com o risco de se perder o sentido de ouvir e cruzar informações provenientes de várias fontes, algo essencial para a atividade jornalística. 
Quanto às peças jornalísticas com origem em agências noticiosas, verificou-se que, durante o período de estreias, muito raramente se recorre a conteúdos produzidos por agências. Contudo, se alargarmos o espectro de análise para toda a cobertura online à área do cinema (e não apenas ao momento das estreias), verificamos que $18,7 \%$ tiveram a assinatura da Agência Lusa e $18,2 \%$ das peças publicadas não foram assinadas.

\section{A crítica como principal género jornalístico}

Além da componente informativa (inerente ao jornalismo), o jornalismo de cinema tem um papel fundamental na formação do público, nomeadamente através de um género jornalístico específico: a crítica. Esta deve "ensinar a ver, informar sobre o que se vê, contextuar, ensinar, e pôr as questões pertinentes a propósito de um filme, fazer saber interrogá-lo" (Cunha, 2004: 88).

A crítica foi o género jornalístico mais frequente na cobertura online das estreias em 2019, seguida da notícia. No caso da crítica, o jornal que mais contribuiu nesse sentido foi o Público. Contudo, embora no quadro teórico a crítica seja encarada como "a operação de um juízo de valor sobre a obra, uma argumentação fundamentada e justificada sobre o valor estético ou outro" (Cunha, 2004: 87) e considerada como um dos géneros de maior exigência intelectual do jornalismo, aquilo que se verificou nas críticas de cinema publicadas nas páginas online dos jornais portugueses foi que, maioritariamente, utilizaram um estilo discursivo descritivo, em que praticamente se relata a narrativa do fil- 
me e são esquecidas as orientações pelas quais a crítica se rege enquanto género jornalístico e que Tito Cardoso e Cunha (2004) enuncia.

Esta tendência vai ao encontro daquilo que Dora Santos Silva (2014) refere quando diz que,

"a crítica acaba por perder, infelizmente, o seu espaço, sendo substituída por géneros híbridos, como a review ou o roteiro, onde os elementos de apreciação da obra, quando existem, são legitimados por juízos de valor do quotidiano" (Santos Silva, 2014: 47).

Também nas páginas online dos jornais analisados se verificou que grande parte das peças são duplicadas das versões impressas desses órgãos de comunicação social. Isto, por um lado, reflete, de certa forma, uma despreocupação pela versão online do jornal, encarando a versão impressa como o espaço primordial de publicação sem um investimento em conteúdos adaptados para os diferentes meios. Por outro lado, pode-se encarar este facto como uma falta de recursos humanos para trabalhar em ambas as versões.

\section{A multimédia inexistente}

$\mathrm{Na}$ apresentação online das peças jornalísticas, aquilo que se verificou foi que estas são, regra-geral, acompanhadas por fotogramas dos filmes, fotografias dos atores e realizadores, por vezes em galeria, ou os respetivos trailers. Contudo, há publicações como o Jornal de Notícias ou o Público que apostam em 
conteúdos em formato de vídeo. No primeiro caso, são frequentemente disponibilizados vídeos onde um jornalista apresenta as estreias da semana e vídeos com entrevistas exclusivas a atores e realizadores. No caso do jornal Público, a prática comum é, todas as semanas, ser publicado um vídeo em formato de compilação dos trailers das estreias da semana.

Por sua vez, no website do Cinebox, da TVI24, os conteúdos que são disponibilizados não são elaborados pela equipa do programa de televisão, mas por jornalistas da editoria digital da TVI. O que se verificou como a grande aposta desta página online foi a multiplicação de excertos do programa de televisão. Isto mostra, tal como referido anteriormente, que as páginas online funcionam como um espaço de duplicação dos conteúdos informativos dos jornais ou dos programas de televisão.

No entanto, no ambiente digital que vivemos, em que o jornalismo dispõe de um vasto leque de possibilidades de storytelling onde se incluem as narrativas imersivas e interativas, não deixa de ser curioso que estas opções sejam praticamente inexistentes. Se, por um lado, assistimos a uma grande aposta na aplicação destas opções em jornais internacionais, como o The New York Times, por outro, nas versões online dos jornais portugueses, as opções de storytelling como a hipertextualidade, a interatividade ou a multimédia são raramente observadas. 


\section{Conclusões}

Apesar de este estudo pertencer a uma investigação mais alargada, pudemos apontar as principais tendências do jornalismo de cinema online no caso concreto das estreias dos filmes. Percebemos que as estreias se constituem como o principal momento de cobertura noticiosa no que ao cinema diz respeito e que a determinação da agenda de estreias é proveniente da indústria à qual as rotinas jornalísticas se adaptam. Neste sentido, os jornais continuam a servir não só enquanto uma janela do marketing, mas também como uma plataforma de legitimação pública, confirmação e reprodução dos filmes enquanto filmes, ou seja, tendo relevância noticiosa, bem como um importante fenómeno cultural (Kristensen \& From, 2015a: 488).

Verificámos também que raramente se recorre a fontes de informação, que a crítica é o principal género jornalístico utilizado no momento das estreias e que as narrativas digitais interativas são uma paisagem ainda distante. Entendemos, portanto, que, neste âmbito do jornalismo de cinema, ainda há um caminho a triIhar no sentido de existir uma crítica que "ensine a ver", com um estilo discursivo maioritariamente interpretativo e que as peças jornalísticas recorram a fontes essenciais para a informação que transmitem. Além disso, um maior investimento em recursos e trabalho criativo na elaboração das peças jornalísticas sobre cinema para o meio online, onde desejavelmente deixasse, de forma gradual, de existir uma duplicação de peças provenientes da versão impressa do jornal, mas sim conteúdos pensados, estruturados e criados para o meio online, com todas as possibilidades de storytelling que daí advêm. 


\section{Bibliografia}

Balsemão, F. P. (1993). O Jornalismo sobre Cinema. Em Expresso, Jornalismo e Cinema. Lisboa: Expresso - Cinemateca Portuguesa, pp. 9-10.

Baptista, C. (2014). Dez Anos de Jornalismo Cultural em Portugal (20002010) Traços e Tendências. In C. Baptista (Ed.), Cultura na Primeira Página: O Lugar da Cultura no Jornalimo Contemporâneo - Caderno de Reflexões (1a ed.). Lisboa: Mariposa Azual, pp. 9-20.

Cunha, T. C. (2004). Argumentação e Crítica (1a ed.). Coimbra: Minerva.

Faro, J. S. (2014). Jornalismo Cultural: informação e crítica, mais que entretenimento. In J. S. Faro, Apontamentos sobre Jornalismo e Cultura (1a ed.) São Paulo: Buqui, pp. 32-51.

Ferreira, F. (21 de Dezembro de 2019). Onde vamos ver os filmes? Expresso - Revista E, pp. 66-67.

Kovach, B., \& Rosenstiel, T. (2005). Os Elementos do Jornalismo: o que os profissionais do jornalismo devem saber e o público exigir. Porto: Porto Editora.

Kristensen, N. N., \& From, U. (2013). Blockbusters as Vehicles for Cultural Debate in Cultural Journalism. Akademisk Kvarter, 7, pp. 5165.

Kristensen, N. N., \& From, U. (2015a). Publicity, News Content, and Cultural Debate: The Changing Coverage of Blockbuster Movies in Cultural Journalism. Communication, Culture \& Critique, 8, pp. 485501.

Lopes, F. (2016). Uma proposta de um modelo taxonómico para a classificação de fontes de informação. Observatorio (OBS*), 10(4), pp. 180-191.

Lourenço, J. (2016). Um Olhar sobre o Jornalismo de Cinema na Televisão Portuguesa: o Caso do Cinebox da TVI24. Tese de Mestrado. Lisboa: Escola Superior de Comunicação Social.

Lourenço, J., \& Subtil, F. (2017). Tendências e Desafios do Jornalismo de Cinema na Televisão Portuguesa: O Caso do Cinebox. In S. Pereira, \& M. Pinto (Ed.), Literacia, Media e Cidadania - Livro de Atas do 4o Congresso. Braga: CECS, pp. 238-250. 
Mesquita, M. (13 de Maio de 2001). A cultura na primeira página, Público, 2 de Novembro de 2015, disponível em: http://www.publico. pt/espaco-publico/jornal/a-cultura-na-primeira-pagina-157678

Piza, D. (2003). Jornalismo Cultural (1a ed.). São Paulo: Contexto.

Santos Silva, D. (2012). Cultura \& Jornalismo Cultural: Tendências e Desafios no Contexto das Indústrias Culturais e Criativas (1a ed.). Porto: Media XXI.

Santos Silva, D. (2014). A Nova Dimensão Performativa do Jornalismo Cultural - Contributos do Roteiro e da Review. In C. Baptista, Cultura na Primeira Página: O lugar da Cultura no Jornalismo Contemporâneo Caderno de Reflexões (1a ed.). Lisboa: Mariposa Azual, pp. 37-49.

Santos Silva, D. (2015). Cultural Journalism in a Digital Environment. New Models, Practices and Possibilities. Tese de Doutoramento. Lisboa: Faculdade de Ciências Sociais e Humanas da Universidade Nova de Lisboa. 